\title{
Developing an Empirical Relationship to Predict Tensile Strength of Friction Stir Welded AA2219 Aluminum Alloy
}

\author{
K. Elangovan, V. Balasubramanian, and S. Babu
}

\author{
(Submitted June 19, 2007; in revised form January 3, 2008)
}

\begin{abstract}
AA2219 aluminum alloy (Al-Cu-Mn alloy) has gathered wide acceptance in the fabrication of lightweight structures requiring a high strength-to-weight ratio and good corrosion resistance. Friction stir welding (FSW) process is an emerging solid state joining process in which the material that is being welded does not melt and recast. This process uses a nonconsumable tool to generate frictional heat in the abutting surfaces. The welding parameters such as tool rotational speed, welding speed, axial force, etc., and tool pin profile play a major role in deciding the joint strength. An attempt has been made to develop an empirical relationship between FSW variables to predict tensile strength of the friction stir welded AA2219 aluminum alloy. To obtain the desired strength, it is essential to have a complete control over the relevant process parameters to maximize the tensile strength on which the quality of a weldment is based. Therefore, it is very important to select and control the welding process parameter for obtaining maximum strength. To achieve this various prediction methods such as response surface method (RSM), analysis of variance (ANOVA), Student's $t$-test, coefficient of determination, etc., can be applied to define the desired output variables through developing mathematical models to specify the relationship between the output parameters and input variables. Four factors, five levels central composite design have been used to minimize number of experimental conditions. The developed mathematical relationship can be effectively used to predict the tensile strength of FSW joints of AA2219 aluminum alloy at $95 \%$ confidence level.
\end{abstract}

Keywords AA2219 aluminum alloy, analysis of variance, axial force, design of experiments, friction stir welding, rotational speed, tensile strength, tool pin profile, welding speed

\section{Introduction}

Aluminum alloy 2219 is a heat treatable wrought alloy developed by Aluminium Company of America (ALCOA) for applications at temperatures up to $315^{\circ} \mathrm{C}$. AA2219 is basically Al-Cu-Mn ternary alloy with the minor additions of Ti, V, and $\mathrm{Zr}$ (Ref 1). It is the most widely and successfully used cryogenic aluminum alloy and flown in various launch vehicles. It has good combination of strength and toughness at cryo temperatures coupled with excellent weldability that has made this alloys an obvious choice for fabrication of cryogenic tanks (Ref 2). Though AA2219 has got an edge over its counterparts in terms of weldability, it also suffers from poor as welded joint strength. The joint strength is only about $40 \%$ when compared to the base metal strength in T87 condition. This is true both in autogenous welds as well as those welded with the matching filler 2319, which contains slightly higher contents of $\mathrm{Ti}$ and $\mathrm{Zr}$ (Ref 3$)$.

K. Elangovan, Department of Production Engineering, Sathyabama University, Chennai, Tamil Nadu, India; and V. Balasubramanian and S. Babu, Department of Manufacturing Engineering, Annamalai University, Annamalai Nagar 608 002, Tamil Nadu, India. Contact e-mail: visvabalu@yahoo.com.
Compared to many of the fusion welding processes that are routinely used for joining structural alloys, friction stir welding (FSW) is an emerging solid state joining process in which the material that is being welded does not melt and recast (Ref 4). Friction stir welding was invented at The Welding Institute (TWI), UK in 1991. Friction stir welding is a continuous, hot shear, autogenous process involving nonconsumable rotating tool of harder material than the substrate material (Ref 5). Defect-free welds with good mechanical properties have been made in a variety of aluminum alloys, even those previously thought to be not weldable. When alloys are friction stir welded, phase transformations that occur during the cool down of the weld are of a solid-state type. Due to the absence of parent metal melting, the new FSW process is observed to offer several advantages over fusion welding (Ref 6).

The formation of defect-free friction stir processed (FSP) zone is affected by the material flow behavior under the action of rotating nonconsumable tool (Ref 7$)$. However, the material flow behavior is predominantly influenced by the FSW tool profiles, FSW tool dimensions, and FSW process parameters (Ref 8,9$)$. Most of the published papers are focusing on the effect of FSW parameters and tool profiles on tensile properties and microstructure formation. The joint efficiency of friction stir welded AA2219-T87 is considerably lower, but it is comparatively higher than the efficiency achieved through fusion and high-energy beam welding processes (not exceeding $50 \%$ ). Some investigators achieved higher joint efficiencies in AA2219-O condition not in T-87 condition (Ref 10). Though the flow patterns influence consolidation of welds in FSW process, this investigation is focused more on static to dynamic volume ratio and corresponding tensile properties to make efficient joints. Hence, an attempt has been made to develop an empirical relationship to predict tensile strength of friction stir 
welded AA2219 aluminum alloy incorporating FSW parameters using statistical tools such as design of experiments, analysis of variance (ANOVA), etc.

\section{Experimental Work}

The rolled plates of $6 \mathrm{~mm}$ thickness, AA2219 aluminum alloy, were cut into the required size $(300 \mathrm{~mm} \times 150 \mathrm{~mm})$ by power hacksaw cutting and milling. Square butt joint configuration $(300 \mathrm{~mm} \times 300 \mathrm{~mm})$ was prepared to fabricate FSW joints. The initial joint configuration was obtained by securing the plates in position using mechanical clamps. The direction of welding was normal to the rolling direction. Single pass welding procedure was followed to fabricate the joints. Nonconsumable tools, made of high-carbon steel were used to fabricate the joints. The chemical composition and mechanical properties of base metal are presented in Table 1. An indigenously designed and developed machine (15 HP; 3000 RPM; $25 \mathrm{KN}$ ) was used to fabricate the joints. Five different tool pin profiles, as shown in Fig. 1, were prepared and used to fabricate the joints.

From the literature (Ref 4-9) and the previous work done in our laboratory (Ref 11,12$)$, the predominant factors which are having greater influence on tensile strength of friction stir welded aluminum alloys were identified. They are: (i) tool pin profiles (ii) tool rotational speed (iii) welding (traverse) speed, and (iv) axial (downward) force. Trial experiments were conducted to determine the working range of the above factors. Feasible limits of the parameters were chosen in such a way that the friction stir welded joints should be free from any visible external defects. The important factors that are influencing the tensile properties of FSW joints and their working range for AA2219 aluminum alloy are presented in Table 2.
Due to wide range of factors, it was decided to use four factors, five levels, central composite design matrix to prescribe the required number of experimental conditions. Table 3 shows the 31 sets of coded conditions used to form the design matrix. First, 16 experimental conditions are derived from full factorial experimental design matrix $\left(2^{4}=16\right)$. All the variables at the intermediate $(0)$ level constitute the center points while the combinations of each process variable at either its lowest $(-2)$ or its highest $(+2)$ with the other three variables of the intermediate levels constitute the star points. Thus the 31 experimental conditions allowed the estimation of the linear, quadratic, and two-way interactive effects of the variables on the tensile strength of FSW joints. The method of designing such matrix is dealt elsewhere $(\operatorname{Ref} 13,14)$. Due to the nature of the welding process and the noise variation, it is typical and reasonable to present process characteristics with a nonlinear quadratic model. It has also been proved by several researchers that efficient use of statistical design of experimental
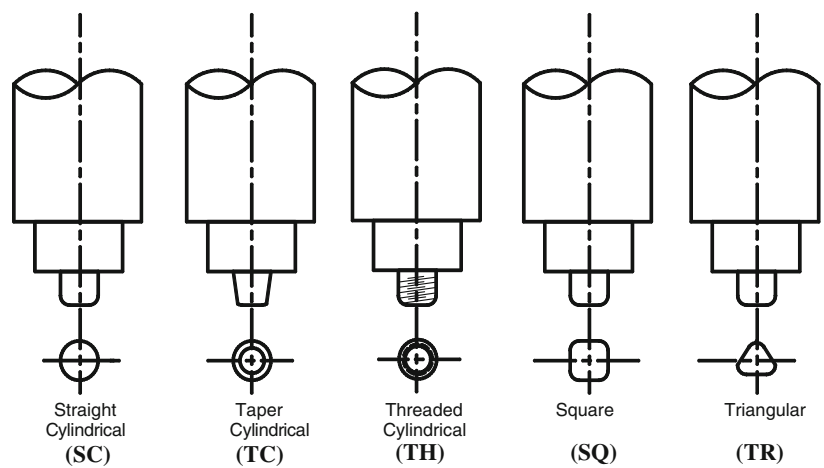

Fig. 1 Different types of tool pin profiles

Table 1 (a) Chemical composition (wt.\%) and (b) mechanical properties of base metal

\begin{tabular}{|c|c|c|c|c|c|c|c|c|}
\hline Elements & Mg & Mn & $\mathbf{F e}$ & $\mathbf{S i}$ & $\mathbf{C u}$ & $\mathbf{Z r}$ & $\mathbf{T i}$ & Al \\
\hline \multicolumn{9}{|c|}{ (a) Chemical composition } \\
\hline AA2219-T87 & 0.01 & 0.27 & 0.13 & 0.01 & 6.7 & 0.12 & 0.05 & Bal \\
\hline Material & \multicolumn{2}{|c|}{$\begin{array}{c}\text { Yield strength, } \\
\text { MPa }\end{array}$} & \multicolumn{2}{|c|}{$\begin{array}{l}\text { Ultimate tensile } \\
\text { strength, MPa }\end{array}$} & \multicolumn{2}{|c|}{ Elongation, \% } & \multicolumn{2}{|c|}{$\begin{array}{c}\text { Vickershardness } \\
(0.5 \mathrm{~kg})\end{array}$} \\
\hline
\end{tabular}

(b) Mechanical properties

AA2219-T87

310

402

23

140

Table 2 Important factors and their levels

\begin{tabular}{|c|c|c|c|c|c|c|c|c|}
\hline \multirow[b]{2}{*}{ No. } & \multirow[b]{2}{*}{ Parameter } & \multirow[b]{2}{*}{ Notation } & \multirow[b]{2}{*}{ Unit } & \multicolumn{5}{|c|}{ Levels } \\
\hline & & & & $(-2)$ & $(-1)$ & (0) & $(+1)$ & $(+2)$ \\
\hline 1. & Tool profile & $P$ & $\cdots$ & $\mathrm{SC}$ & $\mathrm{TH}$ & SQ & TR & $\mathrm{TC}$ \\
\hline 2. & Rotational speed & $N$ & RPM & 1400 & 1500 & 1600 & 1700 & 1800 \\
\hline 3. & Welding speed & $S$ & $\mathrm{~mm} / \mathrm{s}$ & 0.25 & 0.5 & 0.75 & 1.00 & 1.25 \\
\hline 4. & Axial force & $F$ & $\mathrm{KN}$ & 8 & 10 & 12 & 14 & 16 \\
\hline
\end{tabular}

SC: Straight cylindrical pin profiled tool; TH: Threaded cylindrical pin profiled tool; SQ: Square pin profiled tool; TR: Triangular pin profiled tool; TC: Tapered cylindrical pin profiled tool 
Table 3 Design matrix and experimental results

\begin{tabular}{|c|c|c|c|c|c|}
\hline \multirow[b]{2}{*}{ Experiment number } & \multicolumn{4}{|c|}{ Factors } & \multirow[b]{2}{*}{ Tensile strength, MPa } \\
\hline & $\boldsymbol{P}$ & $N$ & $S$ & $\boldsymbol{F}$ & \\
\hline 1 & -1 & -1 & -1 & -1 & 176 \\
\hline 2 & +1 & -1 & -1 & -1 & 198 \\
\hline 3 & -1 & +1 & -1 & -1 & 189 \\
\hline 4 & +1 & +1 & -1 & -1 & 211 \\
\hline 5 & -1 & -1 & +1 & -1 & 195 \\
\hline 6 & +1 & -1 & +1 & -1 & 217 \\
\hline 7 & -1 & +1 & +1 & -1 & 207 \\
\hline 8 & +1 & +1 & +1 & -1 & 228 \\
\hline 9 & -1 & -1 & -1 & +1 & 188 \\
\hline 10 & +1 & -1 & -1 & +1 & 213 \\
\hline 11 & -1 & +1 & -1 & +1 & 201 \\
\hline 12 & +1 & +1 & -1 & +1 & 222 \\
\hline 13 & -1 & -1 & +1 & +1 & 206 \\
\hline 14 & +1 & -1 & +1 & +1 & 228 \\
\hline 15 & -1 & +1 & +1 & +1 & 218 \\
\hline 16 & +1 & +1 & +1 & +1 & 236 \\
\hline 17 & -2 & 0 & 0 & 0 & 165 \\
\hline 18 & +2 & 0 & 0 & 0 & 185 \\
\hline 19 & 0 & -2 & 0 & 0 & 198 \\
\hline 20 & 0 & +2 & 0 & 0 & 207 \\
\hline 21 & 0 & 0 & -2 & 0 & 182 \\
\hline 22 & 0 & 0 & +2 & 0 & 210 \\
\hline 23 & 0 & 0 & 0 & -2 & 190 \\
\hline 24 & 0 & 0 & 0 & +2 & 210 \\
\hline 25 & 0 & 0 & 0 & 0 & 247 \\
\hline 26 & 0 & 0 & 0 & 0 & 233 \\
\hline 27 & 0 & 0 & 0 & 0 & 239 \\
\hline 28 & 0 & 0 & 0 & 0 & 235 \\
\hline 29 & 0 & 0 & 0 & 0 & 244 \\
\hline 30 & 0 & 0 & 0 & 0 & 249 \\
\hline 31 & 0 & 0 & 0 & 0 & 245 \\
\hline
\end{tabular}

techniques, allows development of an empirical methodology, to incorporate a scientific approach in the welding procedure (Ref 15-17).

During preliminary trial runs, the process parameters in middle level show defect-free joints. To check the repeatability, the last seven experiments have been made with the middle level. From the literatures (Ref 18, 19), it is observed that the straight cylindrical (ST) and taper cylindrical (TC) pin profiles yielded comparatively poor tensile strength. Hence these pin profiles have been considered in experiments 17 and 18 with single trial.

For the convenience of recording and processing experimental data, upper and lower levels of the factors have been coded as +2 and -2 , respectively. The coded values of the any intermediate values can be calculated using the following relationship (Ref 13).

$X_{i}=2\left[2 X-\left(X_{\max }+X_{\min }\right)\right] /\left(X_{\max }-X_{\min }\right)$

where $X_{i}$ is the required coded value of a variable $X ; X$ is any value of the variable from $X_{\min }$ to $X_{\max } ; X_{\min }$ is the lowest level of the variable; and $X_{\max }$ is the highest level of the variable.

As prescribed by the design matrix thirty-one joints were fabricated. The welded joints were sliced (as shown in Fig. 2a) using a power hacksaw and then machined to the required dimensions as shown in Fig. 2(b). Three tensile specimens were fabricated as per the American Society for Testing of Materials (ASTM E8M-04) standards to evaluate the tensile strength of the joints. Tensile strength of the FSW joints were evaluated by conducting test in Universal Testing Machine and the average of the three results is presented in Table 3.

\section{Developing an Empirical Relationship}

The response function tensile strength (TS) of the joints is a function of tool profile $(P)$, rotational speed $(N)$, welding speed $(S)$ and axial force $(F)$, and it can be expressed as

$\mathrm{TS}=f(P, N, S, F)$

The second-order polynomial (regression) equation used to represent the response surface ' $Y$ ' is given by

$Y=b_{0}+\sum b_{i} x_{i}+\sum b_{i i} x_{i}^{2}+\sum b_{i j} x_{i} x_{j}$

and for four factors, the selected polynomial could be expressed as

$$
\begin{aligned}
\mathrm{TS}= & b_{0}+b_{1}(P)+b_{2}(N)+b_{3}(S)+b_{4}(F)+b_{11}\left(P^{2}\right)+b_{22}\left(N^{2}\right) \\
& +b_{33}\left(S^{2}\right)+b_{44}\left(F^{2}\right)+b_{12}(P N)+b_{13}(P S) \\
& +b_{14}(P F)+b_{23}(N S)+b_{24}(N F)+b_{34}(S F)
\end{aligned}
$$

where $b_{\mathrm{o}}$ is the average of responses and $b_{1}, b_{2}, \ldots b_{23}$ are the coefficients that depend on respective main and interaction effects of the parameters. The value of the coefficients has been calculated using the following expressions (Ref 13).

$$
\begin{aligned}
b_{0}= & 0.142857\left(\sum Y\right)-0.035714 \sum \sum\left(X_{i i} Y\right) \\
b_{i}= & 0.041667 \sum\left(X_{i} Y\right) \\
b_{i i}= & 0.03125 \sum\left(X_{i i} Y\right)+0.00372 \sum \sum\left(X_{i i} Y\right) \\
& -0.035714\left(\sum Y\right) \\
b_{i j}= & 0.0625 \sum\left(X_{i j} Y\right)
\end{aligned}
$$

All the coefficients were tested for their significance at $95 \%$ confidence level (CI) applying student's $t$-test using SPSS statistical software package. After determining the significant coefficients, the final relations were developed using only these coefficients. The final mathematical relationship between FSW variables to predict tensile strength of FSW joints, developed by the statistical design of experiments procedure are given below:

$$
\begin{aligned}
T S=\{ & 240.86+6.71(P)+4.38(N)+9.29(S)+5.96(F) \\
& -14.66\left(P^{2}\right)-8.17\left(N^{2}\right)-10.54\left(S^{2}\right)-13.79\left(F^{2}\right) \\
& -1.68(P S)-1.44(P F)-2.19(S F)\} \mathrm{MPa} \quad \ldots
\end{aligned}
$$

The adequacy of the developed relationship is tested using the ANOVA technique (ANOVA). As per this technique, if the calculated value of the $F_{\text {ratio }}$ of the developed relationship is less than the standard $F_{\text {ratio }}$ (from $F$-table) value at a desired level of confidence (say 95\%), then the relation is said to be adequate within the confidence limit. ANOVA test results are presented in Table 4 for both the relations. From 
(a)

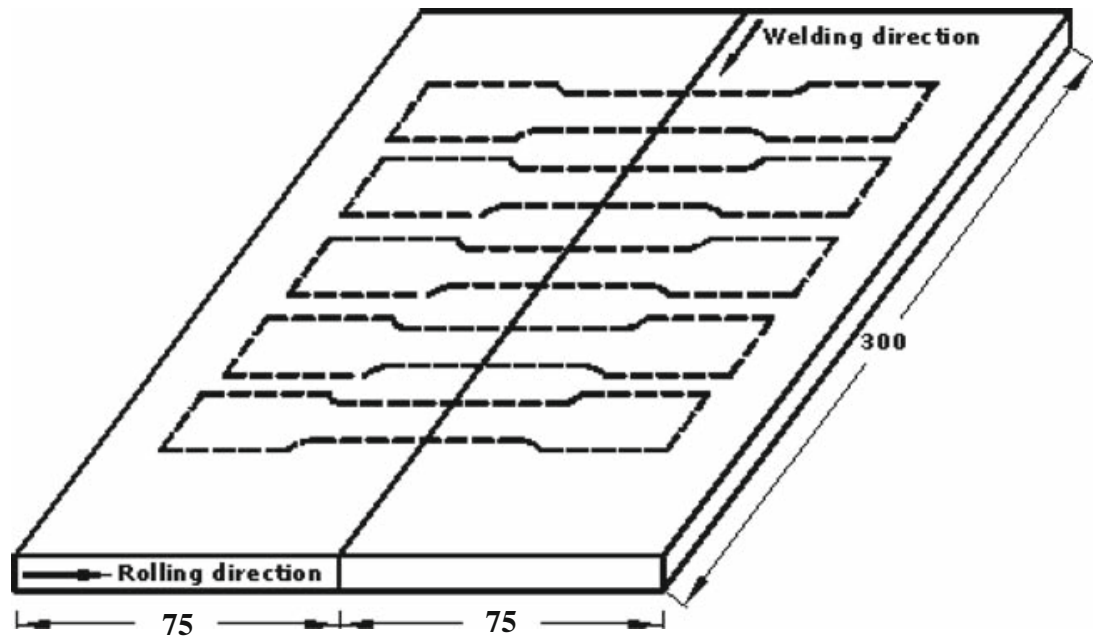

(b)

R 12.5

ASTM E8M-04



Fig. 2 Dimensions of tensile specimen (a) scheme of welding with respect to rolling direction and extraction of tensile specimens. (b) Dimensions of tensile specimen. All dimensions are in ' $\mathrm{mm}$ '

Table 4 ANOVA test results

\begin{tabular}{ll}
\hline Terms & \\
\hline First-order terms & 4652.5 \\
$\quad$ Sum of squares (SS) & 4 \\
$\quad$ Degrees of freedom (dof) & 1163.1 \\
$\quad$ Mean square (MS) & \\
Second-order terms & 8920.9 \\
$\quad$ Sum of squares (SS) & 10 \\
$\quad$ Degrees of freedom (dof) & 892.09 \\
Mean square (MS) & \\
Error terms & 225.42 \\
Sum of squares (SS) & 6 \\
$\quad$ Degrees of freedom (dof) & 37.57 \\
Mean square (MS) & \\
Lack of fit & 1477.1 \\
$\quad$ Sum of squares (SS) & 10 \\
Degrees of freedom (dof) & 147.71 \\
Mean square (MS) & 3.931 \\
$F_{\text {ratio }}$ (calculated) & 4.06 \\
$F_{\text {ratio }}(10,6,0.05)$ & Yes \\
\hline Whether the model is adequate?
\end{tabular}

the table, it is understood that the developed mathematical relationships are found be adequate at $95 \%$ CI. Coefficient of determination ' $r$ ', is used to find how close the predicted and experimental values lie. The value of ' $r$ ', for the abovedeveloped relations are presented in Table 5, which indicates high correlation exist between experimental values and predicted values.

\section{Discussion}

Mathematical relations developed in the preceding section was written in $\mathrm{C}$ program and the developed $\mathrm{C}$ program was used to estimate the tensile strength of friction stir welded AA2219 aluminum alloy joints for different combinations of FSW parameters. Predicted values are plotted as graphs and they are displayed in Fig. 3-5. The plotted graphs can be effectively used to understand the effect of FSW parameters such as tool rotational speed, welding speed, axial force, and tool profile on tensile strength of friction stir welded AA2219 aluminum alloy joints.

\subsection{Effect of Tool Rotational Speed}

The yield strength and tensile strength of all the joints are lower than that of the base material, irrespective of the tool rotational speeds used to fabricate the joints. Of the five tool rotational speeds used to fabricate AA2219 joints, the joint fabricated at a rotational speed of 1600 RPM yielded superior tensile properties. Figure 3 reveals the effect of tool rotational speed on tensile strength of friction stir welded AA2219 aluminum alloy. At lower rotational speed (1400 RPM), the tensile strength of FSW joints is lower. When the rotational speed is increased from 1400 RPM, correspondingly the tensile strength also increased and reaches a maximum at 1600 RPM. If the rotational speed is increased above 1600 RPM, the tensile strength of the joint decreased. This trend is common in all the joints irrespective of tool pin profile. 
Table 5 Comparison between experimental and predicted values

\begin{tabular}{|c|c|c|c|c|}
\hline Parameters & Experimental tensile strength, $\mathrm{MPa}$ & Predicted tensile strength, MPa & Variation, $\%$ & $r^{2}$ \\
\hline$P=\mathrm{SC} ; N=1500 ; S=0.5 ; F=14$ & 123 & 130.30 & -7.3 & 0.92 \\
\hline$P=\mathrm{TC} ; N=1500 ; S=0.75 ; F=10$ & 170 & 166.22 & +3.78 & \\
\hline$P=\mathrm{TH} ; N=1600 ; S=1.0 ; F=12$ & 224 & 219.92 & +4.08 & \\
\hline$P=\mathrm{SQ} ; N=1700 ; S=0.5 ; F=8$ & 141 & 145.78 & -4.78 & \\
\hline$P=\mathrm{TR} ; N=1400 ; S=0.75 ; F=14$ & 186 & 182.20 & +3.8 & \\
\hline
\end{tabular}

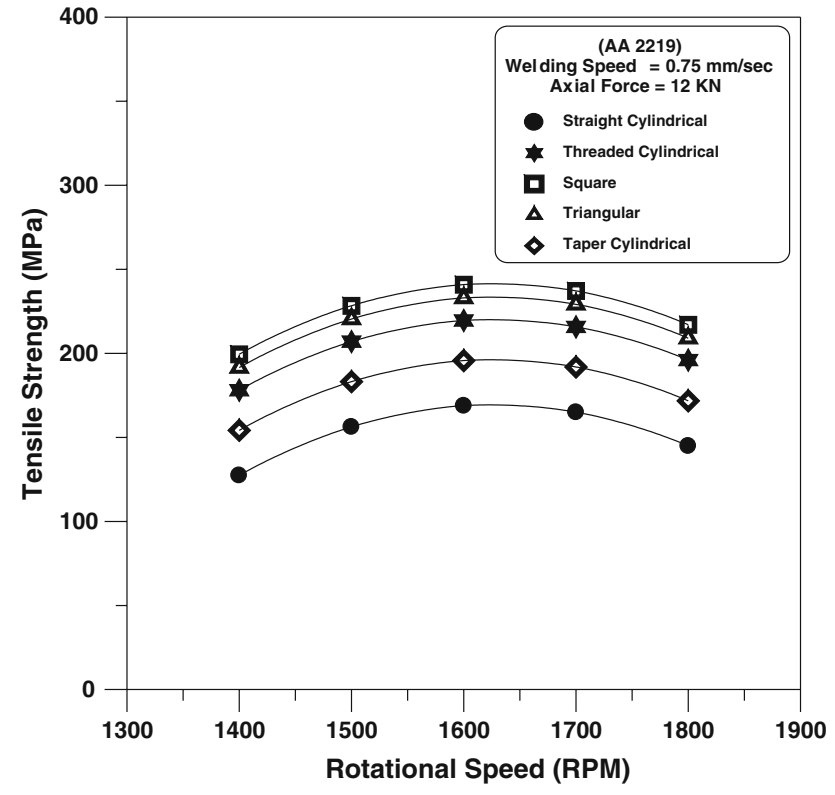

Fig. 3 Effect of rotational speed on tensile strength

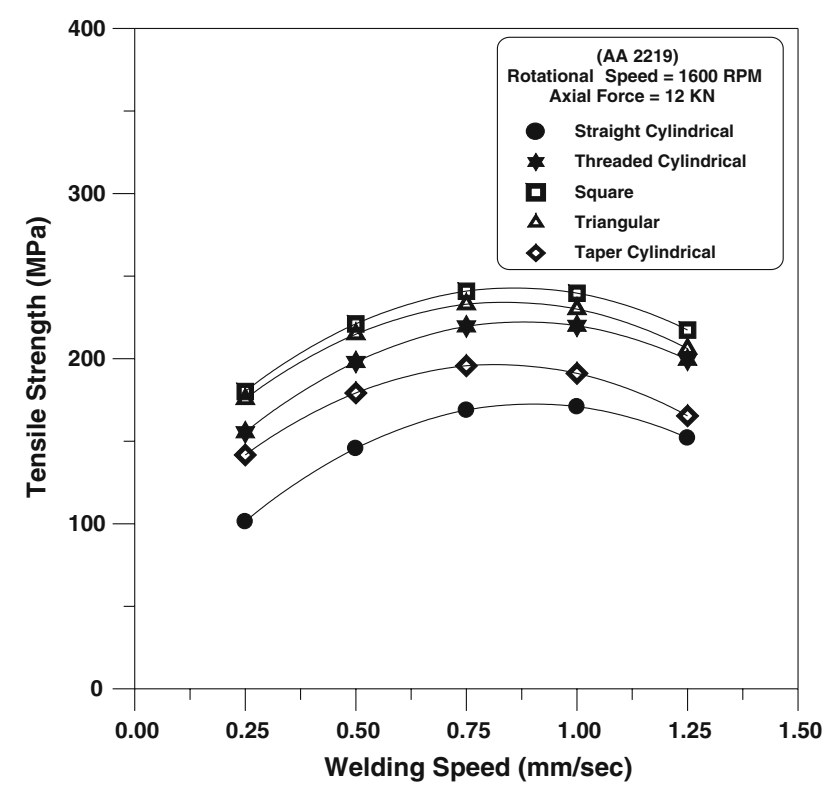

Fig. 4 Effect of welding speed on tensile strength

The tensile properties and fracture locations of the joints are to a large extent, dependent on the rotational speed, and other parameters. When the joints are associated with defects like

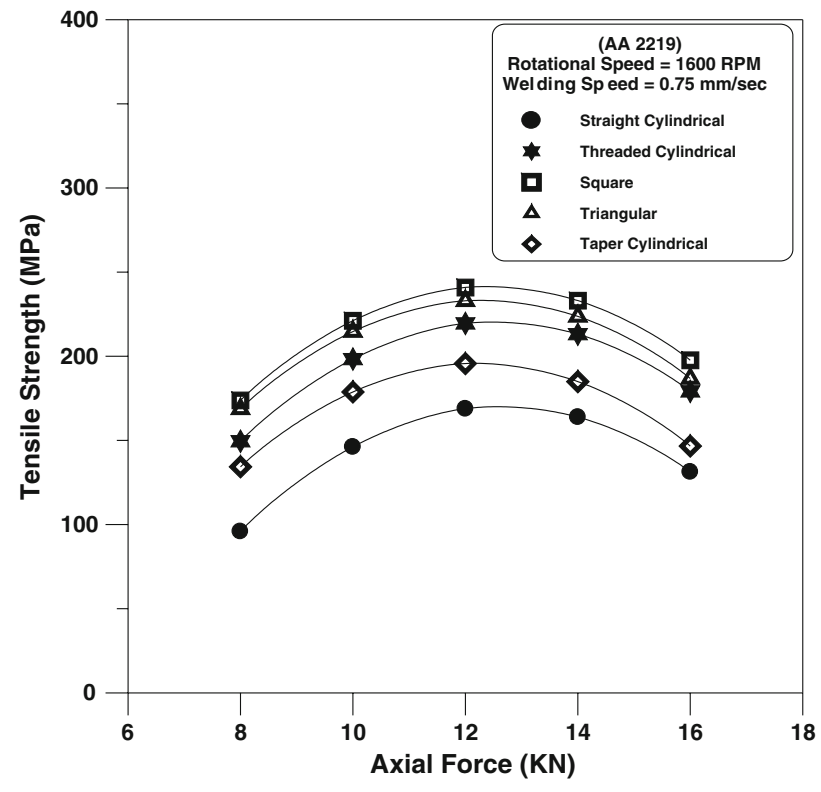

Fig. 5 Effect of axial force on tensile strength

pinhole, tunnel, and cracks in the FSP region, the joints failed at the defective area and if the joints are defect free, the failure locations shifted to lowest hardness zone. Macrostructure observations showed that the joints fabricated at lower rotational speeds (1400 RPM) contained defects like pinhole or tunnel in FSP region as shown in Table 6 and resulted in lower tensile properties. On the other hand, joints fabricated at higher rotational speeds (1800 RPM) as shown in Table 6, contained large-size defects and it appeared like a tunnel (Ref 11). As rotational speed increased, the heat input per unit length of the joint increased, resulting inferior tensile properties due to rise in temperature, which increases grain growth. Considerable increase in turbulence, which destroys the regular flow behavior available at lower speed, is also observed.

Moreover a higher-rotational speed causes excessive release of stirred materials to the upper surface, which resultantly left voids in the weld zone. Fracture surface observations confirmed that the grooves or insufficient consolidation of the material is visible corresponding to the tunnel or pinhole exists in the macrostructure. On the other side, the area of the weld zone decreases with decreasing the tool rotation speed and affect the temperature distribution in the weld zone. This lower heat input condition resulted in lack of stirring and yielded lower joint strength.

\subsection{Effect of Welding Speed}

Figure 4 reveals the effect of welding speed on tensile strength of friction stir welded AA2219 aluminum alloy. At lower 


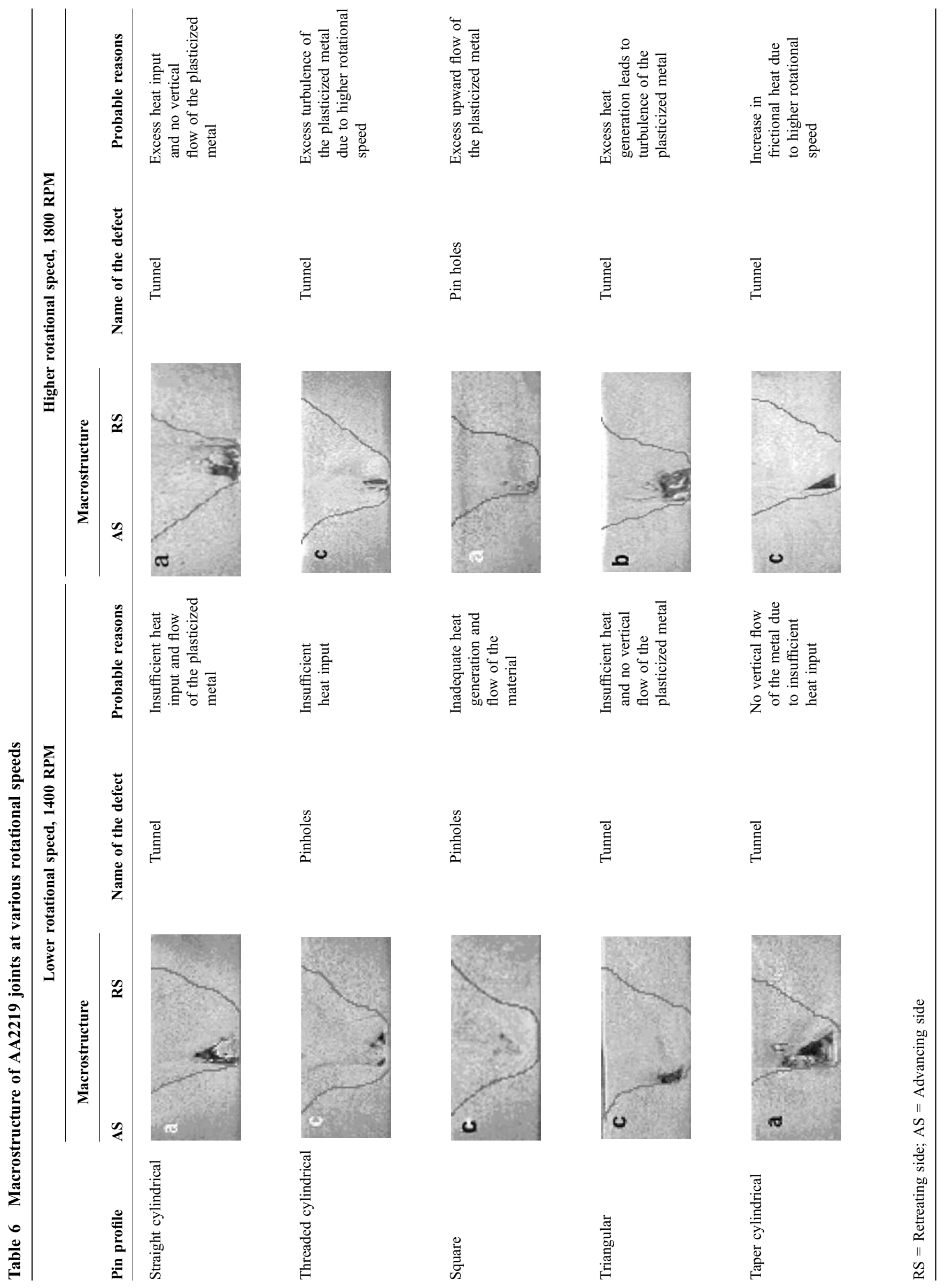




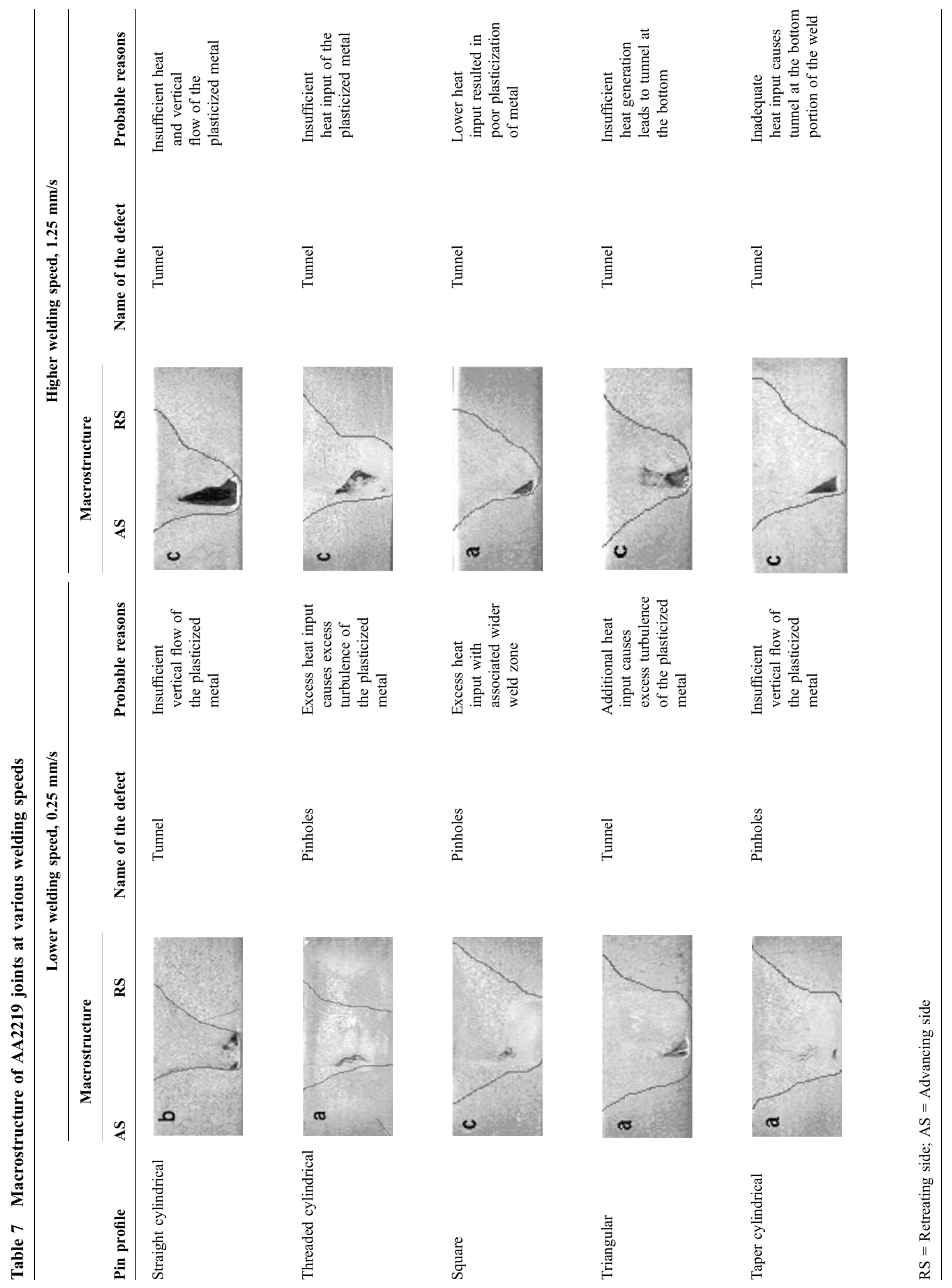




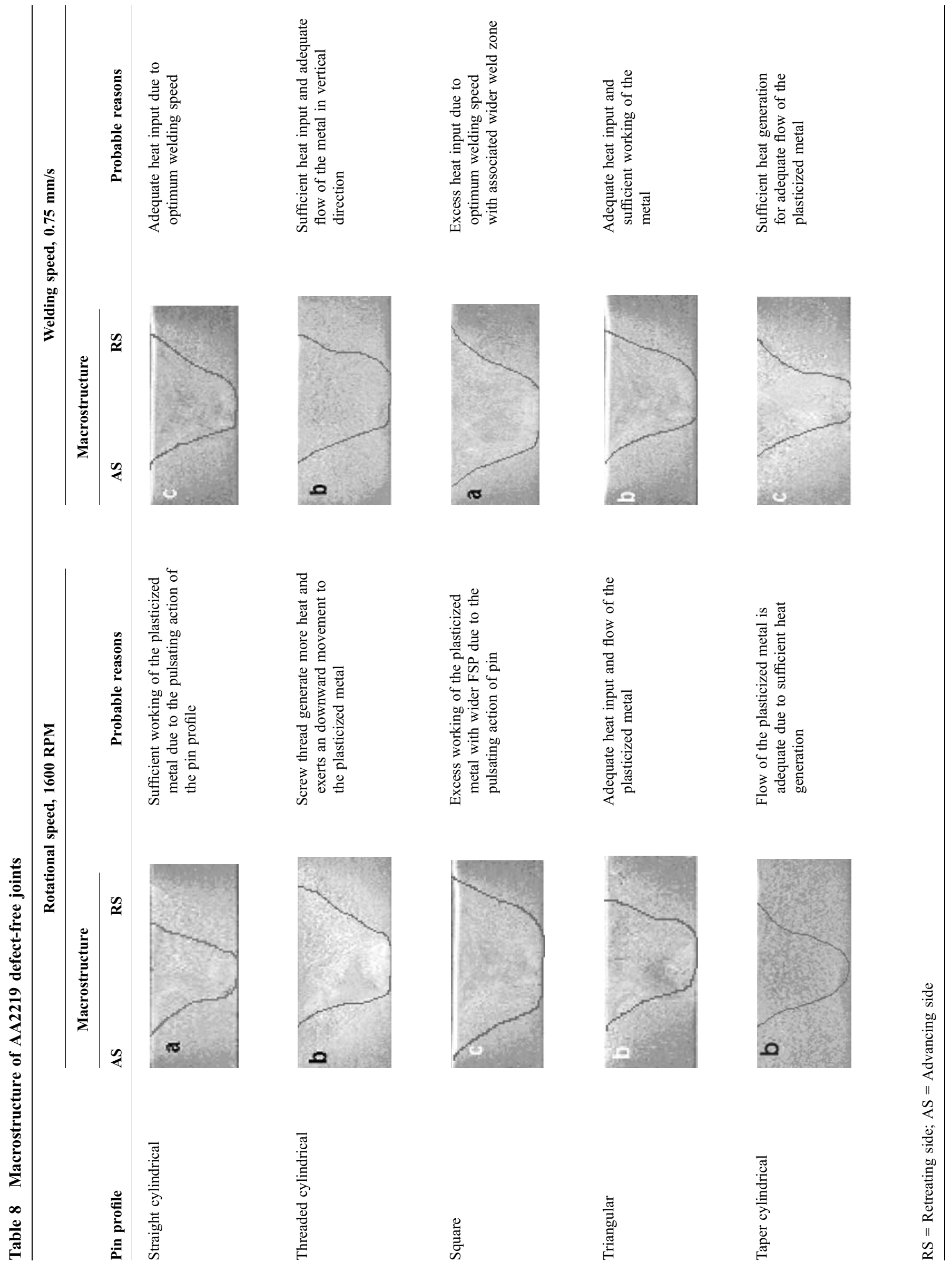


welding speed $(0.25 \mathrm{~mm} / \mathrm{s})$, tensile strength of the FSW joints is lower. When the welding speed is increased from $0.25 \mathrm{~mm} / \mathrm{s}$, correspondingly the tensile strength also increased and reaches a maximum at $0.75 \mathrm{~mm} / \mathrm{s}$. If the welding speed is increased above $0.75 \mathrm{~mm} / \mathrm{s}$, the tensile strength of the joint decreased. This trend is common in all the joints irrespective of tool pin profile.

When the joints are associated with defects like pinhole, tunnel, and cracks in the FSP region, the joints failed at the defective area and if the joints are defect free, the failure locations shifted to lowest hardness zone. Macrostructure observations showed that the joints fabricated at lower welding speeds $(0.25 \mathrm{~mm} / \mathrm{s})$ as shown in Table 7 contained defects like pinhole or crack in FSP region and resulted in lower tensile properties. On the other hand, joints fabricated at higher welding speeds $(1.25 \mathrm{~mm} / \mathrm{s})$ as shown in Table 7 contained large-size defects and it appeared like tunnel (Ref 20). In general, FSW at higherwelding speeds results in short exposure time in the weld area with insufficient heat and poor plastic flow of the metal and causes some voids like defects in the joints. It seems that these voids are formed due to poor consolidation of the metal interface when the tool travels at higher-welding speeds. The reduced plasticity and rates of diffusion in the material may have resulted in a weak interface.

The welding speed has a strong impact on productivity in streamlined production of FSW of aluminum alloy sections. A significant increase in welding speed is achieved with highweld quality and excellent joint properties. The softened area is narrower for the higher-welding speed than that for the lowerwelding speed. Thus, the tensile strength of as welded aluminum alloy has a proportional relationship with welding speed (Ref 21). Higher-welding speeds are associated with low heat inputs, which result in faster cooling rates of the welded joint. This can significantly reduce the extent of metallurgical transformations taking place during welding (such as solubilization, re-precipitation, and coarsening of precipitates) and hence the local strength of individual regions across the weld zone (Ref 22).

When the welding speed is slower than a certain critical value, the FSW can produce defect-free joints (Table 8). When the welding speed is faster than the critical value, welding defects can be produced in the joints. The defects act as a crack initiation site during tensile test. Therefore, the tensile properties and fracture locations of the joints are determined by the welding speed (Ref 10). The fracture location of the joint gradually changes to the retreating side from the advancing side of the joint as the welding speed is gradually increased. They further opined that the ultimate tensile strength decreases significantly when the welding speed is increased. The softened area was narrower for the higher-welding speed than that for the lower-welding speed (Ref 23).

\subsection{Effect of Axial Force}

Figure 5 reveals the effect of axial force on tensile strength of friction stir welded AA6061 aluminum alloy. At lower axial force $(8 \mathrm{KN})$ tensile strength of the FSW joints is lower. When the axial force is increased from $8 \mathrm{KN}$, correspondingly the tensile strength also increased and reaches a maximum at $12 \mathrm{KN}$. If the axial force is further increased above $12 \mathrm{KN}$, the tensile strength of the joint decreased. This trend is common in all the joints irrespective of tool pin profile. Macro structure observations presented in the previous article (Ref 12) showed that the joints fabricated at lower axial force $10 \mathrm{KN}$ for
AA2219 contained tunnel defects on the advancing side of the joint resulted in poor tensile strength. On the other hand, joints made with higher axial force of $14 \mathrm{KN}$ for AA2219 showed good weld consolidation, but with excess shear lips on both retreating and advancing side of the welds which also yielded poor tensile properties.

During the FSW process, joining is achieved through frictional heating between the tool and sheet, plasticizing, mixing, and extrusion action of a rotating pin-shoulder tool that moves between two parts being joined (Ref 24). The load characteristics associated with a linear weld have focused upon the forces exerted by the tool, especially the shoulder force that is directly responsible for the plunge depth of the tool pin into the workpiece. A long-time rotation of the tool under the static conditions generates a tremendous amount of heat input, and allows the material to become very hot and plastic. The shoulder force that is directly responsible for the plunge depth of the tool pin into the surface of the workpiece is very changeable during the plungement. The stirring action completely obliterates any remnants of the joint line. Two effects are responsible for the creation of the material flow in the weld zone. First is the extrusion process, where the applied forces and the motion of the tool pin propel the material after it has undergone the plastic deformation. The second is due to the rotation of the pin that serves as the driving force for the flow (Ref 25).

The heat input and temperature distribution during FSW is due to frictional heat generation between the rotating tool shoulder and surface of the plate to be welded and in turn depends on coefficient of friction. Apart from the properties of tool and plate material, the axial force decides the coefficient of friction. Hence axial force plays a significant role in FSW process. The degree of material mixing and inter diffusion, the thickness of deformed aluminum lamellae, the material flow patterns highly depends on welding temperature, flow stress, and axial force (Ref 26).

One of the important requirements for FSW process is to keep the well-plasticized material with suitable temperature under the area of the shoulder of the tool. Higher hydrostatic pressure due to excess axial force along the joint line causes a substantial amount of flash on both the advancing and retreating side of the weld. It is likely that this flash formation is due to excess heat input caused by higher rotational speed and a lower welding speed and higher downward force. The large mass of the flash is ejected to the outside due to softening of the metal excessively. And also, the formation is the result of inadequate transport of weld metal around the retreating side of the tool. As the pin and associated plug of attached material advance through the plate, if the swept volume transported around the retreating side, then the excess will be expelled from the weld region as flash resulted in inferior tensile properties. Though the weld consolidation is good with defect-free FSP zone, formation of shear lips resulted in excess thinning of the metal in the weld area yielding poor tensile properties (Ref 27).

\subsection{Effect of Tool Profile}

The primary function of the nonconsumable rotating tool pin is to stir the plasticized metal and move the same behind it to have good joint. Pin profile plays a crucial role in material flow and in turn regulates the welding speed of the FSW process. Friction stir welds are characterized by well-defined weld nugget and flow contours, almost spherical in shape, these contours are dependent on the tool design and welding parameters and 
process conditions used. Oosterkamp et al. (Ref 28) identified the role of tool pin in the FSW, the tool pin is to shear the material to its back during translation of the tool and the inserted rotating pin brings the material at both sides of the joint line to the plastic state, aided by frictional heat input of the shoulder.

Figures 3-5 shows the effect of tool pin profile on tensile strength of friction stir welded AA2219 aluminum alloy. Of the five joints, the joints fabricated by square pin profiled tool exhibiting highest tensile strength irrespective of welding parameters. Next to square pin profile, triangular pin profiled tool showing almost matching tensile properties to that of square pin followed by threaded, taper, and ST pins, respectively. The reason for better properties with tool pin having flat faces like square, triangular is as below.

Tools with noncircular profile will allow plasticized material to pass around the probe. Pin profiles with flat faces are associated with eccentricity. This eccentricity of the rotating object is related to dynamic orbit. Every type rotary machine is associated with dynamic orbit due to eccentricity. This eccentricity must to a greater or lesser extent be part of the FSW process characteristics. Eccentricity allows hydro mechanically incompressible plasticized material to flow more easily around the probe. It follows that a nominal bias of center or noncircular probe will also allow plasticized material to pass around the probe. Essentially it is the relationship between the greater volume of the 'dynamic orbit' of the probe and the volume of the static displacement of the probe that helps providing a path for the flow of plasticized material from the leading edge to the trailing edge of the rotating tool (Ref 4).

The relationship between the static volume and swept volume decides the path for the flow of plasticized material from the leading edge to the trailing edge of the rotating tool. This ratio is equal to 1 for ST, 1.09 for tapered cylindrical, 1.01 for threaded cylindrical, 1.56 for square, and 2.3 for triangular pin profiles (Ref 10). In addition, the triangular and square pin profiles produce a pulsating stirring action in material flow. The square pin profile produces $104 \mathrm{pulses} / \mathrm{s}$ and triangular pin profile produces 78 pulses/s at a speed of 1600 RPM. Moreover, the eccentricity of the lobes of the square and triangular pins assisting the breaking up of the oxides of the metal resulted in superior tensile properties. Though the ratio of the swept volume of the triangular pin is higher than the square pin profile, better tensile properties of square pin profile is due to increased number of pulses/s for the given speed.

\section{Conclusions}

(1) A mathematical relationship has been developed to predict the tensile strength of friction stir welded AA2219 aluminum alloy joints by incorporating welding parameters and tool profiles using statistical tools such as design of experiments, ANOVA, and regression analysis.

(2) The joints fabricated using square pin profiled tool with a rotational speed of $1600 \mathrm{RPM}$, welding speed of $0.75 \mathrm{~mm} / \mathrm{s}$, and axial force of $12 \mathrm{KN}$ exhibited superior tensile properties compared to other joints.

\section{Acknowledgments}

The authors are grateful to the Department of Manufacturing Engineering, Annamalai University, Annamalai Nagar, Tamil Nadu,
India for extending the facilities of Metal Joining Laboratory and Materials Testing Laboratory to carryout this investigation. The authors also wish to express their sincere thanks to Aeronautical Research \& Development Board (ARDB), Ministry of Defence, New Delhi for the financial support to carryout this investigation through sponsored project No. DARO/08/1061356/M/I.

\section{Open Access}

This article is distributed under the terms of the Creative Commons Attribution Noncommercial License which permits any noncommercial use, distribution, and reproduction in any medium, provided the original author(s) and source are credited.

\section{References}

1. C. Huang and S. Kou, Effect of Post Weld Heat Treatment on Mechanical and Metallurgical Properties of Heat Treatable Aluminum Alloys, Weld. J., 2000, 79(5), p 113s-120s

2. G.I. Dance, Comparative Evaluation of Mechanical Properties of TIG, MIG, EBW and VPPA welded AA2219 Aluminum Alloy, Weld. Metal Fabric., 1994, 24, p 216-222

3. J.A. Hartman, R.J. Beil, and G.T. Hahn, Effect of Copper Rich Regions on Tensile Properties of VPPA Weldments of 2219-T87 Aluminum Alloy, Weld. J., 1987, 66, p 73s-83s

4. W.M. Thomas and E.D. Nicholas, Friction Stir Welding for the Transportation Industries, Mater. Design, 1997, 18, p 269-273

5. F. Olga Valerio, Micro Structural Issues in a Friction Stir Welded Aluminium Alloy, Script. Mater., 1998, 38(5), p 703-708

6. G. Cao and S. Kou, Friction Stir Welding of 2219 Aluminium: Behaviour of $\theta\left(\mathrm{Al}_{2} \mathrm{Cu}\right)$ Particles, Weld. J., 2005, p 1-s-8-s

7. Y.C. Chen, H. Liu, and J. Feng, Friction Stir Welding Characteristics of Different Heat-Treated-State 2219 Aluminium Alloy Plates, Mater. Sci. Eng. A, 2006, 420, p 21-25

8. W.B. Lee, Y.-M. Yeon, and S.-B. Jung, Mechanical Properties Related to Micro Structural Variation of 6061 Al Alloy Joints by Friction Stir Welding, Mater. Trans., 2004, 45(5), p 1700-1705

9. H.J. Liu and H. Fuji, Mechanical Properties of Friction Stir Welded Joints of 1050-H 24 Aluminium Alloy, Sci. Technol. Weld. Join., 2003, 8(6), p 450-454

10. K. Elangovan and V. Balasubramanian, Effect of Pin Profile and Rotational Speed of the Tool on the Formation of Friction Stir Processing Zone in AA6061 Aluminium Alloy, J. Mater. Manuf. Process., 2008, 23(3), p 251-260

11. K. Elangovan and V. Balasubramanian, Influences of Pin Profile and Rotational Speed of the Tool on the Formation of Friction Stir Processing Zone in AA2219 Aluminium Alloy, Mater. Sci. Eng. A, 2007, 459, p 19-34

12. K. Elangovan and V. Balasubramanian, Effect of Tool Pin Profile and Axial Force on the Formation of Friction Stir Processing Zone in AA6061 Aluminium Alloy, Int. J. Adv. Manuf. Technol., doi 10.1007/s00170-007-1100-2

13. G.E.P. Box, W.H. Hunter, and J.S. Hunter, Statistics for Experiments. John Wiley Publications, New York, 1978

14. I. Miller, J.E. Freund, and R. Johnson, Probability and Statistics for Engineers. Prentice of Hall of India Pvt. Ltd, New Delhi, 1999

15. K. Manonmani, N. Murugan, and G. Bhuvanasekaran, Effect of Process Parameters on the Weld Bead Geometry of Leaser Beam Welded Staineless Steel Sheets, Int. J. Join. Mater., 2005, 17(4), p 103-109

16. V. Gunaraj and N. Murugan, Application of Response Surface Methodology for Predicting Weld Bead Quality in Submerged Arc Welding of Pipes, J. Mater. Process. Technol., 1999, 88, p 266-275

17. T. Senthilkumar, V. Balasubramanian, and M.Y. Sanavullah, Influences of Pulsed Current Tungsten Inert Gas Welding Parameters on Tensile Properties of AA6061 Aluminium Alloy, J. Mater. Design, 2007, 28(7), p 2080-2092

18. M. Boz and A. Kurt, The Influence of Stirrer Geometry on Bonding and Mechanical Properties in Friction Stir Welding Process, Mater. Design, 2004, 25, p 343-347 
19. H. Fujii, L. Cui, M. Maeda, and K. Nogi, Effect of Tool Shape on Mechanical Properties and Micro Structure of Friction Stir Welded Aluminium Alloys, Mater. Sci. Eng. A, 2006, A 419, p 25-31

20. K. Elangovan, and V. Balasubramanian, Effect of Pin Profile and Welding Speed on Tensile Properties of Friction Stir Welded AA6061 Aluminium Alloy, Int. J. Microstr. Mech. Prop., (2007), (under review)

21. W.B Lee, Y.M. Yeon, and S.-B. Jung, The Joint Properties of Dissimilar Formed Aluminium Alloys by Friction Stir Welding According to the Fixed Location of Materials, Scrip. Mater., 2003, 49, $\mathrm{p} 423-428$

22. S. Lomolino, R. Tovo, and J. Dos Santos, On the Fatigue Behaviour and Design Curves of Friction Stir Butt Welded Al Alloys, Int. J. Fatigue, 2005, 27, p 305-316

23. E.B.F. Lima, J. Wegener, C. Dalle Donne, G. Goerigk, T. Wroblewski, T. Buslaps, A.R. Pyzalla, and W. Reimers, Dependence of the Microstructure, Residual Stresses and Texture of AA 6013 Friction
Stir Welds on the Welding Processes, Z. Metallkd, 2003, 94(8), p $908-915$

24. G. Buffa, J. Hua, R. Shivpuri, and L. Fratini, A Continuum Based FEM Model for Friction Stir Welding-Model Development, Mater. Sci. Eng., 2006, 419, p 389-396

25. J.H. Ouyang and R. Kovacevic, Material Flow During Friction Stir Welding (FSW) of the Same and Dissimilar Aluminum Alloys, J. Mater. Eng. Perform., 2002, 11(1), p 51-63

26. J. Colligan, J. Paul, Konkol, James J., Fisher, and J.R. Pickens, Friction Stir Welding Demonstrated for Combat Vehicle Construction, Weld. J., 2002, p 1-6

27. Y.G. Kim, H. Fujii, T. Tsumura, T. Komazaki, and K. Nakata, Three Defects Types in Friction Stir Welding of Aluminium Die Casting Alloy, Mater. Sci. Eng. A, 2006, 415, p 250-254

28. A. Oosterkamp, L. Djapic Oosterkamp, and A. Nordeide, Kissing Bond Phenomena in Solid State Welds of Aluminum Alloys, Weld. J., 2004, p 225s-231s 